\title{
Design Assistance for User Interface Designers
}

\author{
Harald Reiterer \\ German National Research Center for Computer Science (GMD), Institute for Applied Information Technology, \\ Human-Computer Interaction Research Division, PO. Box 1316D-53731 St. Augustin, E-mail: reiterer(a.gmd.de \\ and \\ University of Vienna. Institute for Applied Computer Science and Information Systems. \\ Liebiggasse 4/3-4, A-1010 Vienua
}

Keywords: Human factors, guidelines, user interface design. UIMS, object-orientation, multimedia.

Abstract: The paper addresses an important research approach in the area of user interface development tools, namely to discover helpful, unobtrusive, structured, and organised ways to integrate the use of guidelines, standards, and style guides into the development tools. The aim of this research approach is to assist the user interface designer during the design process with the help of powerful design aid tools that will lead to user interfaces of high ergonomic quality; an important aspect for the end-users.

\section{THE PROJECT USER INTERFACE DESIGN ASSISTANCE}

Empirical results have shown that most user interface designers have no or only very limited knowledge about human factors for user interface design (Molich and Nielsen 1990, Beimel et al 1992). Therefore most of them were not able to apply standards, sty'leguides, or guidelines in the design process. A great amount of designers prefers computer based design aids, to overcome their lack of human factors expert knowledge. These design aids should be integrated in their design environment. So an important research goal in the area of interface design is to discover helpful, unobtrusive, structured. and organised ways to integrate human factors knowledge (e.g., how to apply human factors principles, guidelines. standards. styleguides. and design rules in the design process) into the design environments without stifling creativity. To reach this research goal a GMD project called "User Interface Designer Assistance (IDA)" was started 1993 with the aim to develop design aid tools for user interface designers (Reiterer 1993, 1993a, 1994). The project belongs to the new GMD research domain: intelligent multimedia systems. One goal of this newv research domain is the development of multimedia-based enabling systems. Prototypes of all important results of this project are now available and can be demonstrated.

To realise the project results the GMD has established cooperations with scientific partners (Fachlochschule
Darmstadt: University of Bonn), with typical users of user interface development tools (Software AG, Darmstadt; SAP AG. Walldorf; Hoechst AG, Frankfurt) and with companies producing UIMS (ISA GmbH; Concept asa, Frankfurt/NSL, Paris). The aim of this co-operation is to develop the project results for specific application domains and to understand the day-to-day operational requirements and constraints placed on user interface designers.

\section{IMPORTANT CHARACTERISTICS ()F THE PROJECT IDA}

Section 2 gives a short sumunary about the important characteristics of the IDA project. In section 3 some selected project results are presented in more detail.

The purpose of the design aid tools is to assist the user interface designers during the design process of the user interface. These design aid tools are integrated in the development tool (UIMS) of the user interface designers. The designers have direct access to human factors knowledge from their design envi ronment.

The primary auclience are user interface designers using user interface development tools. Another important audience is the group of human factors specialists. They could use the design aid tools to assure that the human factors knowledge will be applied in the design process. It's obvious that the design aid tools could not substitute training in the area of human factors (e.g., workshops), but they are a good completion of this training process. The human factors special ists are also responsible for the maintenance of the human factors knowledge of the design aid tools.

To reach standard compliance of user interfaces the human factors guidelines are summarised in a "Human Factors Style Guide", which is the foundation for the computer supported design aid tools. The content of this "Human Factors Style Guide" isn't restricted to constructor styleguides (e.g.. OSF/MOTIF Style Guide, IBM Common User Access, MICROSOFT Windows Style Guide). It's based on a broader approach and includes user interface design requirements from the relevant international standards (e.g., ISO 9241) and the relevant research literature (e.g., Mayhew 1992. Smith and Moiser 1986). The focus of the 
first version of the "Human Factors Style Guide" is on state of the art graphical user interfaces (GUIs). Rescarch activities in the area of new user interfaces (c.g.. multiuser. 3D, multimedia) of other projects of the GMD will be the basis to include new design principles and requirement in the "Human Factors Style Guide".

The implementation type of the human factors guidelines is based on a combination of object-oriented, multimedia (text. sound, pictures, graphics, animation, videos) and knowledge-based techniques. The type of the design aid tools could be characterised as a hybrid combination of different tools: an object-oriented library of a UIMS, a multimedia tool, and an expert system.

Important guideline facilities of the design aid tools are the possibilities to modify and expand the guidelines in the design aid tools. It's not planed to allow the users (interface designers) of the design aid tools to do this. It should be the job of the human factors specialist to maintain the human factors knowledge in the different design aid tools. The users of the design aid tools have the possibility to make annotations in the multimedia documents: to search by keyword or topic in the multimedia documents and in the library of interaction objects: to modify rules of the knowledge base depending on special needs of the task or the enduser.

An important requirement for the IDA project is to realisc tool and platform independent design aid tools. In principle it should be possible to integrate the design aid tools in each C-based UIMS. Therefore different UIMS on different computing platforms are used for the integration of the design aid tools, e.g. the "XFaceMaker" (from NSL. Paris) under OSF/Motif and the "ISA/Dialog Manager" (form ISA $\mathrm{GmbH}$, Stuttgart) under Microsoft Windows.

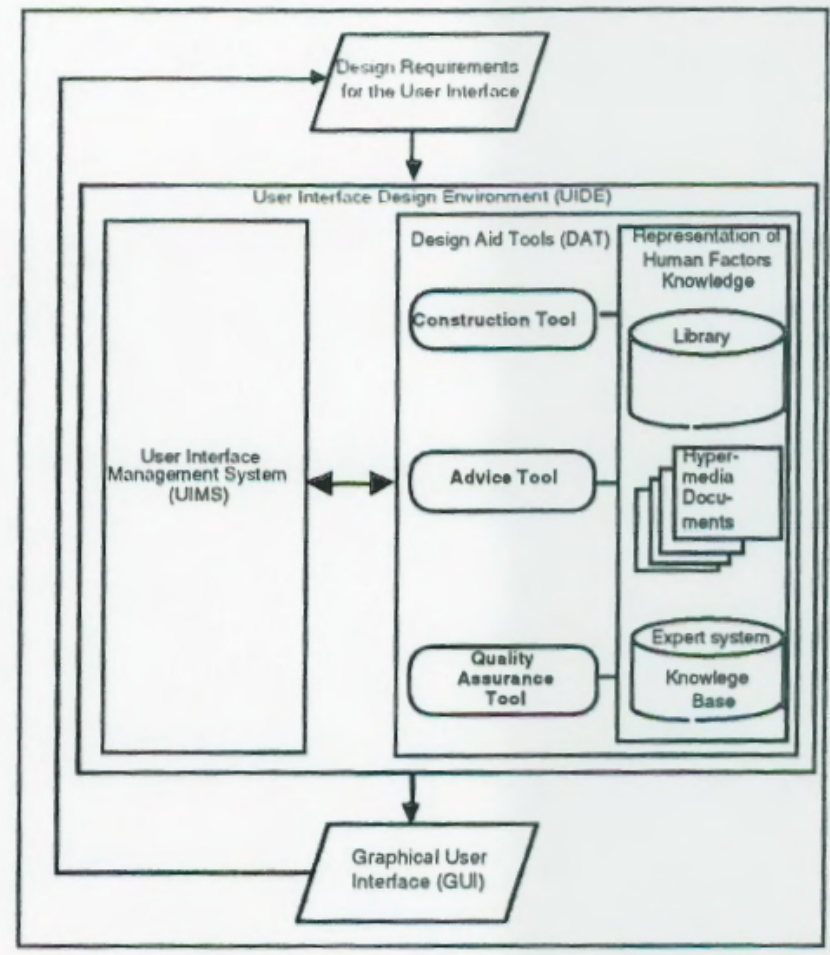

Figure 1. Architecture of the IDA Design Aid Tools.

The design aid tools are available as research products and their status are under ongoing implementation. The GMD has established co-operations with developers of UIMS (ISA GmbH, Stuttgart and Concept asa, Frankfurt/NSL, Paris) with the aim. that the features of the design aid tools will be included in commercial available user interface development tools.

Figure 1 shows the architecture of the clesign aid tools and their integration in a User Interface Design Environment (UIDE). The integration of the design aid tools into the UIDE is important. Separate systems for construction and enabling have major deficiencies. If the argumentation of the enabling system is to serve design. it must do so by informing construction. This can happen only if construction and argumentation are explicitly linked in an integrated design environ ment.

\section{DESIGN A.SSISTANCE THR()IGH DESIGN AID TOOLS}

To present the different design aid tools to the designer in an integrated fashion a control panel called IDA has been realised, which is permanently placed on the screen. Figure 2 shows the IDA control panel placed over the UIMS and a small example of a GUI. which is shown under the UIMS. The designer can communicate with the IDA design aid tools by the help of the control panel and its icons. If the designer wants some advice during the design of a GUI, he activates the relevant icon in the IDA control panel and gets a global or context-sensitive support through the selected design aid tool. A control program behind the IDA control 
panel controls the communication and the data flow between the UIMS and all the design aid tools. There is a clear interface between the UIMS and the different design aid tools. The control program is also responsible for the coordination of the different design aid tools.
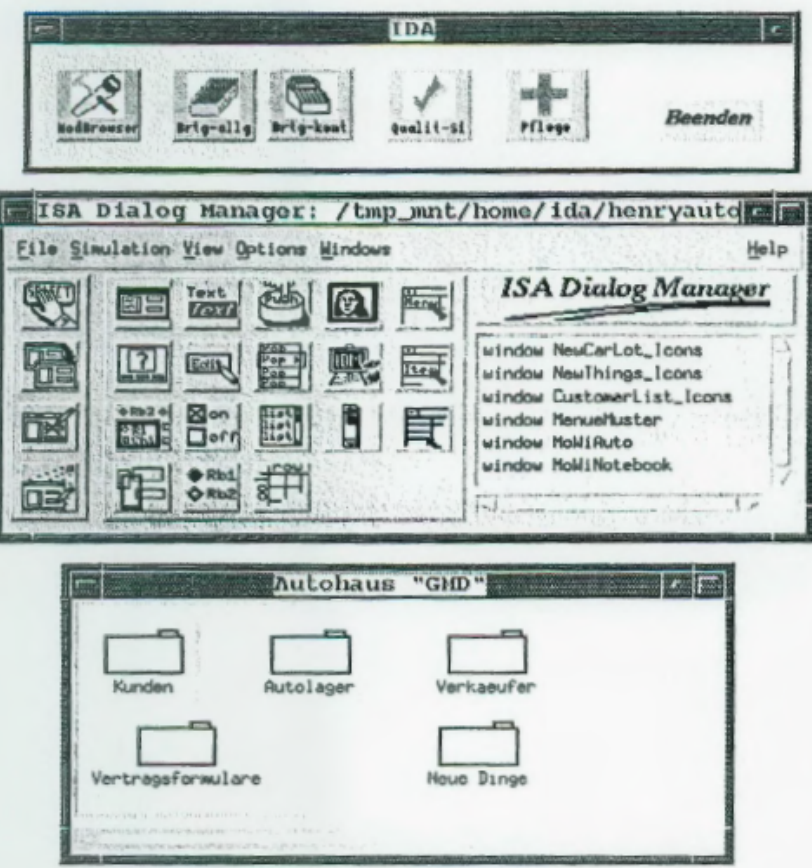

Figure 2. Typical design situation

\subsection{The IDA-Construction Tool}

The IDA-CONSTRUCTION TOOL offers domain-oriented building blocks in a library, such as generic and domainspecific interface objects and dialogue scripts. These interface objects and dialogue scripts have been designed in compliance with the "Human Factors Style Guide". With the help of information retrieval mechanisms the interface designers are able to search through a library for relevant interaction objects or dialogue scripts (templates) and use them as parts of the user interface.

One information retrieval mechanism integrated in the IDA construction tool is a graphical browser, shown in figure 3 The browser is based on a semantic tree. structuring the templates. This structure differentiates the templates from a designer point of view and is based on typical tables of content which one can find in styleguides or guidelines. The designer has the possibility to browse through the library using the semantic tree structure finding a relevant interaction object or dialogue script. If the designer prefers an alpluabetic presentation of the predefined templates, he has the possibility to change the presentation mode.

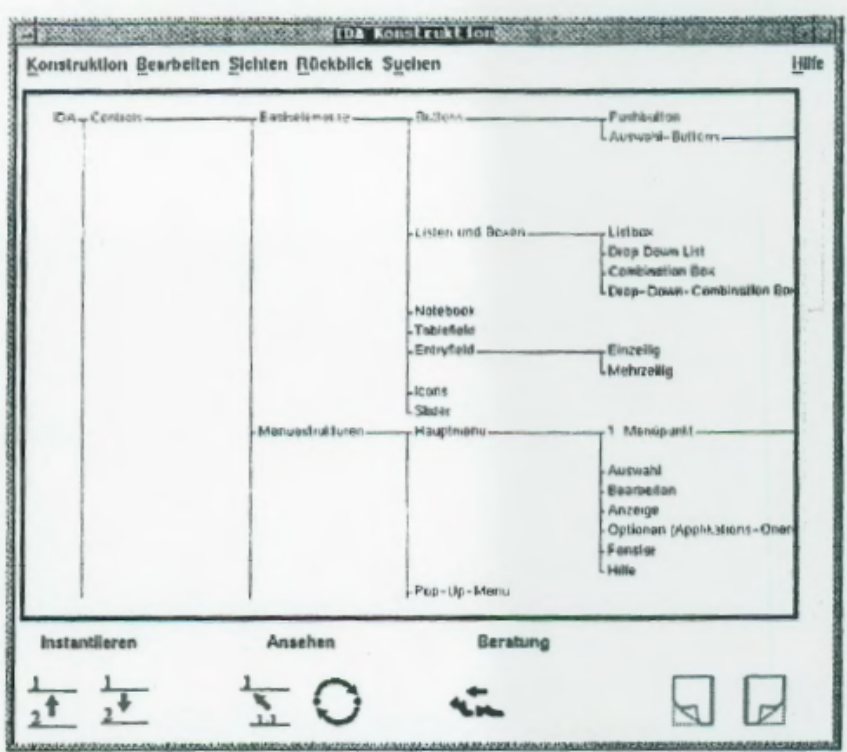

Figure 3. IDA Constnuction tool - graphical browser

If the designer wants to see the look and feel of a template before he makes an instance. he can start a simulation mode that shows the look and feel of the selected model. A visualisation of the template. a list of all dialogue scripts attached to this template and important attributes of the template are presented in separate windows. Figure 4 shows an example. In the left window (entitled "Modell ansehen") the look and feel of a template for typical data entry purposes is shown. In the right window (entitled "Regeln und Attribute") the attached dialogue scripts and important attributes are shown. The designer can now explore all important characteristics of the template, e.g., its look and feel. because the presented visualisation can be used in the same way as the instance of the template.

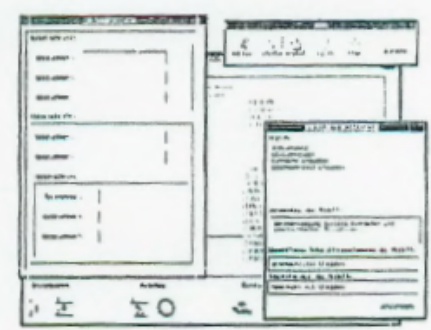

Figure 4. IDA Construction tool - look and feel of a template

If the designer las found a template with the relevant look and feel, he can make an instance of this model (pushing the button "Instantiieren" in the browser window, see figure 3 ). A dialogue box will appear giving the designer the opportunity to costumize the final look and feel of the instance of the template. For example in the dialogue box of figure 5 the designer can define the number of sections of a notebook. the number of pages of each section, the label of 
each tab, etc. This mechanism allows the designer to define the attributes of the instance of the template class in an interactive way. This instance will appear in the working area of the UIMS and can now be used in the construction process of the user interface.

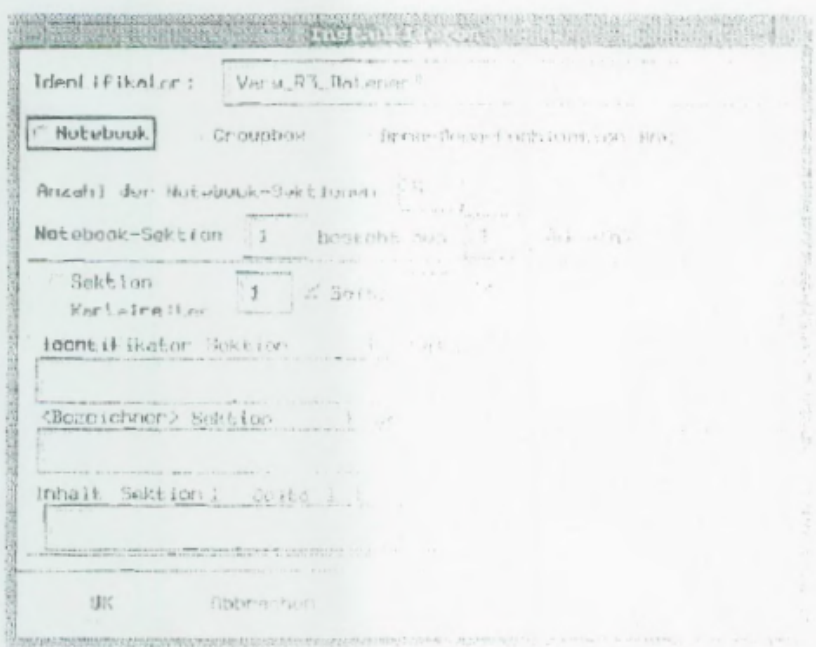

Figure 5. IDA Construction tool - make an instance dialogue

If the designer needs further information when and how to use a specific template, he can activate in a context-sensitive way the advice tool (pushing the button "Beratung" in the browser window, see figure 3 ).

\subsection{The IDA-Achice Tool}

The IDA-ADVICE TOOL has two functions. First it explains the short critique messages of the quality assurance tool in more detail (see section 3.3.). The information is presented with the help of multimedia documents in a graphical, textual and animated form.

The second function of the IDA-advice tool is to support the interface designers by giving global and context-sensitive advise of how to design human factors based graphical interfaces or how to use a specific interaction object. Activating the context-sensitive advice the designer gets some information when and how to use the selected interaction object in the UIMS and what should be the ergonomic "look" and "feel" of this interaction object. The selected object could be a generic interaction object (e.g. push button, list box, edit text), an instance of a template or it could be part of a complex dialogue object. The necessary context information is transferred from the UIMS to the advice tool to select the relevant chapter of the multimedia advice system.

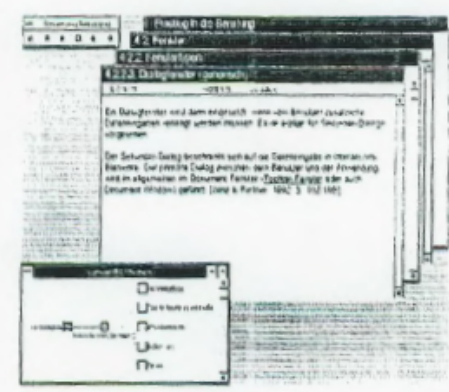

Figure 6. IDA Advice tool - documents and navigation functions

The aim of the advice system is to determine an analogy between the examples of the adviser and the current task of the designer. The designers are aided in building an analogy by assuming that the presented example or information is relevant to their current task. If the designer wants deeper information, for example why the "look" and "feel" of a specific interaction object should be so, he gets it in a hypertextual form. After the activation of the advice tool the designer gets a short definition of the important features of the selected interaction object. Figure 6 shows a typical example of a multimedia document and the navigation functions. Each document includes different navigation functions (menu items. pop-up menu. hot spots, hot links) which allows a differentiated presentation of knowledge.

All important navigation functions are collected in a pop-up menu that will appear after activating the right mouse button in a document (see figure 7).

\begin{tabular}{|c|c|c|c|}
\hline \multicolumn{2}{|l|}{$\begin{array}{l}\text { Exploration } \\
\text { inhaltsstruktur }\end{array}$} & \multirow{2}{*}{\multicolumn{2}{|c|}{ 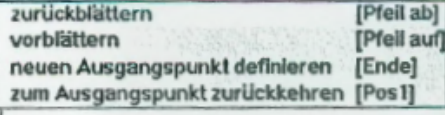 }} \\
\hline \multirow{3}{*}{$\begin{array}{l}\text { Textsuche anzeigen } \\
\text { Stichwortverzeichnis anzelgen } \\
\text { Historylliste anzeigen } \\
\text { Verwandte Themen anzeigen }\end{array}$} & \multirow{3}{*}{$\begin{array}{l}{[\mathrm{F} 2]} \\
{[\mathrm{F} 3]} \\
{[\mathrm{F} 4]} \\
{[\mathrm{F}]}\end{array}$} & & \\
\hline & & & \\
\hline & & & \\
\hline $\begin{array}{l}\text { Tonausgabe generieren } \\
\text { Kapitelnummern anzeigen }\end{array}$ & $\begin{array}{l}\text { [Fb] } \\
\text { [Num] }\end{array}$ & & \\
\hline $\begin{array}{l}\text { Gulded Tour } \\
\text { Hille zur Beratung }\end{array}$ & $\begin{array}{l}\text { [F7] } \\
{[\mathrm{F} 1]}\end{array}$ & & \\
\hline Beratung beenden & & & \\
\hline
\end{tabular}

Figure 7. IDA Advice 10ol - pop-up menu for navigation functions

For the global navigation in all documents of the advice tool a graphical browser. an index and a text query function are available. The graphical browser is based on the same structure as the browser of the construction tool and structures the design knowledge in different sections (nodes). With the help of this browser the designer can browse through all sections of the advice tool searching for an interesting topic. The graphical browser is shown in figure 6 in the window entitled "Vervandte Themen". The index (Stichwortverzeichnis) and the text query function (Textsuche) allow a direct access to interesting topics. Figure 8 shows the dialogue box of the text query function. The query function allows a full text retrieval in all documents using wildcards. 


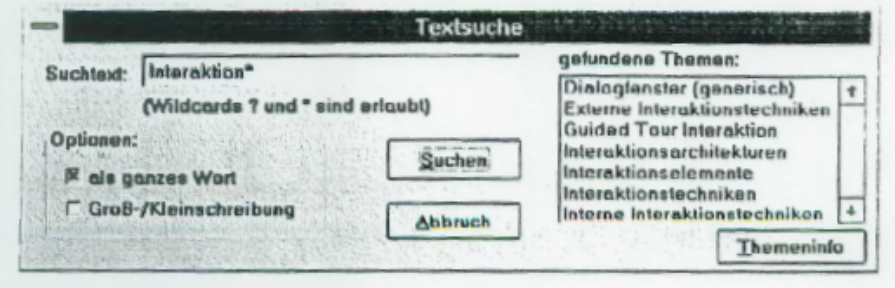

Figure 8. IDA Advice tool - text query function

A different concept to present the design knowledge in a global way is the guided tour "user interface design". The purpose of this guided tour is to explain how graphical user interfaces should be designed considering human factors. Figure 9 shows the start window of the guided tour. On the basis of a user interface development life cycle consisting of six steps all necessary design activities are described. For each development step (Analyse. Dialog, Interaktion, Pragmatik, Praesentation, Evaluation) a predefined sequence of sections through which the designer should go is established. If the designer goes through all six development steps he will have visited all sections of the global advice. This form of presentation allows a guided use of the advice tool and is useful for novice designer in the area of GUI design.

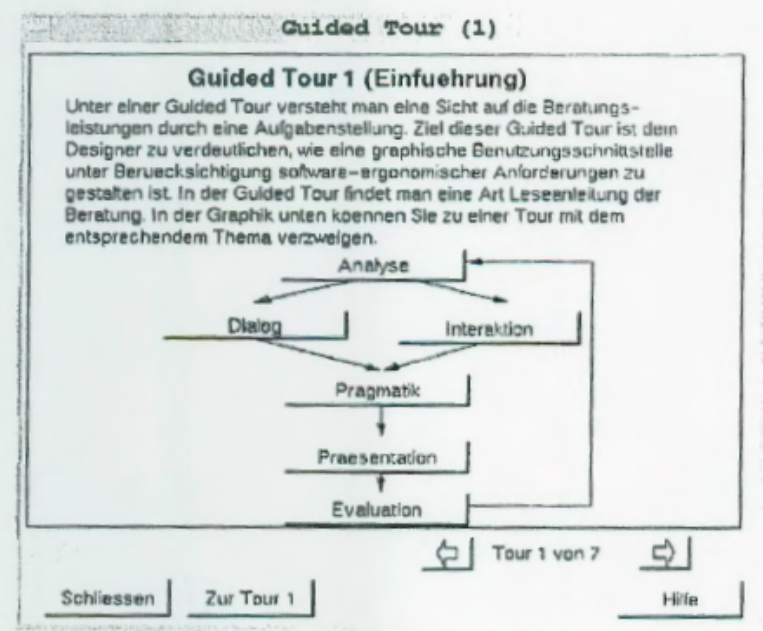

Figure 9. IDA Advice tool - guided tour user interface design

\subsection{The IDA-Quality Assurance Tool}

The IDA-QUALITY ASSURANCE TOOL identifies potential problems in the artifact being designed. It is able to detect and critique partial solutions constructed by the interface designer. With the help of an expert system the knowledge is implemented in a knowledge base as interface objects and condition-action rules, which are tested whenever the designer asked for a quality control. A very similar approach is found in Löwgren and Nordquist (1992).

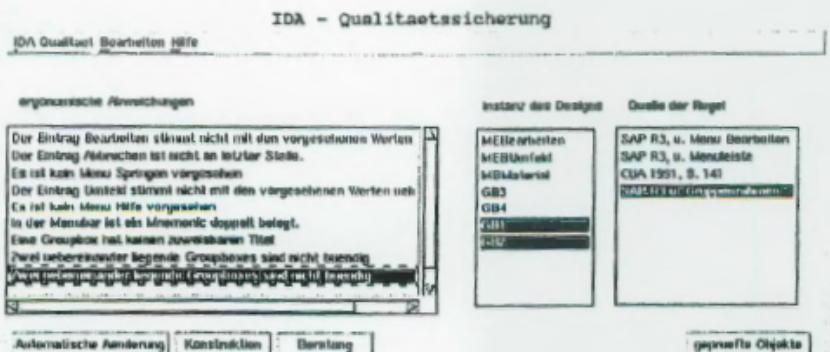

Figure 10. IDA Quality assurance tool - window showing ergonomic deficits

Using the rules of the knowledge base and controlled by an inference mechanism the expert system analysis the conformance of the user interface with the human factors knowledge (analytic critique). This passive form of quality assurance usually evaluates the (partial) product of the design process, not the individual user actions that resulted in the product. The results of the analytic critiquing process are presented with the help of an explanation component in a special window shown in Figure 10. The window of the explanation component contains a short description of all discovered ergonomic deficits (heading "ergonomische Abweichungen"), the source of the short description (heading "Quelle der Regel") and the identifier of the evaluated object (heading "Instanz des Designs") which contains some ergonomic deficits. Now the designer has three possibilities: If he needs further explanation of the comments. he can activate the IDA advice tool (pushing the button "Beratung"). If a specific template is available, the designer can activate the IDA construction tool (pushing the button "Konstruktion"). If the designer selects the identifier of an object, he can activate the object editor of the UIMS (double-clicking the identifier) and can re-implement the interaction object that contains some ergonomic deficits. In some situations it is possible to change the detected deficits automatically. If this is the case the designer can activate a separate dialogue box (activating the button "Automatische Aenderungen") which gives him the opportunity to correct the deficit directly. The benefit for the designer is that he has not to branch in the editor of the UIMS re-implementing the faulty interaction object.

As an important feature of the quality assurance tool, the designer can costumize and extend the tool by modifying or adding interface objects, critique rules, and relationships. This end-user modifiability allows for evolution of the design enviromment as human factor knowledge and design requirements change. Figure 11 shows the dialogue box for a rule modification. The dialogue box shows the actual value of the condition part of the rule (labelled "aktueller Wert in der Wissensbasis:"). The designer can now change this value in a special entry field (labelled "neuer Wert der Wissensbasis:"). After the rule modification the knowledge base will be updated. For all further design evaluations the designer can now use the updated knowledge base or he can also use the original one. 
Regel-Anpassung

Abweichung

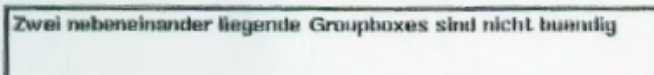

aktueller Wert in der Wssensbasis: (tolerierte Entfemung in Spalten)

\section{3} neuer Wert der Wissensbasis: Wssenshasis Aandern Abbrechen

Figure 11. IDA quality assurance tool - dialogue box for rule modification

It was not the intention of the IDA project to realise a more active form of quality control, where the changes that trigger a critique are operations that modify the design in the work area of the UIMS. When a design principle is violated in an active critiquing system, a critique would fire and display a critique in a message window. Active quality assurance (critique) exercise control over the intervention strategy by critiquing a product or action at an appropriate time (Fischer et al. 1991). They function like active agents by continuously monitoring user actions. Active critics can respond to individual user actions. There are some important problems with an active quality assurance. First, continuously monitoring user actions lead to data protection problems (user profile). Second, active quality assurance is infeasible if a continuous evaluation of the design is computationally too expensive. Third, the intervention of the system can disnupt a cognitive process of the designer. There are various intervention strategies possible, that differ in the degree to which they attract user's attention. but all have some disadvantages. A critique message can force users to attend to the critique by not allowing them to continue with their work. The problem can be corrected immediately without causing dependent problems. But the user may be disrupted during a cognitive process. Users then need to reconstruct the goal structure that existed before the intervention. A less intrusive mode is the display of messages in a separate quality assurance window on the screen. This gives users a choice of whether to read and process the message immediately or first complete an action progress. However, there is a risk that messages go unnoticed. These problems and some principal problems with the agent metaphor are the reasons, why an active form of the quality assurance has not been realised in the IDA project.

\section{OUTLOOK}

Based on the co-operation with industrial partner's application domain specific prototypes of all design aid tools have been developed. The usefulness and usability of these prototypes will now be evaluated in the realistic context of the application domains of the co-operating partners. The results of the evaluation process will be feedbacked in the development process of the design aid tools to improve them.

It is also intended to develop a specific design aid tool supporting the design decision process. With the help of such a tool the rationale for the various user interface design decisions can be made explicit and recorded for later reference (Moran and Carroll 1994). Having access to an audit trail through the design rationale is important during iterative development. Since changes to the interface will often have to be made, it is helpful to know the reasons underlying the original design. Design rationales can be captured in a hypertext structure or with the help of video records of design meetings and selected user tests. It is planed to extent the IDA advice tool with special features for capturing design rationiales based on a special repository including hypertext documents and videos.

\section{REFERENCES}

Beimel J.. Hüttner J, and Wandke H. 1992, Kenntnisse von Programmierern auf dem Gebiet der SoftwareErgonomie: Stand und Möglichkeiten zur Verbessenung. unpublished paper of a lecture on the Fachtagnng der Sektion Arheits-, Betriebs und Organisationspsychologic des Berufsverbandes Deutscher Psychologen "Arheits- Betriebs- und Organisationspsychologice vor Ort" 25.-27.5.1992, Bad Lauterbach.

Fischer G.. Lemke. A.. Mastaglio T. and Morch A. 1991, The role of critiquing in cooperative problem solving. ACM Transactions on Irformation Systems. Vol. 9, No. 3. April 1ฯ91. pp.123-151.

IBM 1992. Object-Oriented Interface Design, IBM Common User Access Guiclelines: Carmel: Que Corporation. $19 \% 2$.

ISO 9241. Ergonomic Requirements for Office Work with Fisual Display Terminals

Löwgren J. and Nordquist T. 19ฯ2. Knowledge-Based Evaluation as Design Support for Graphical User Interfaces. In ( $\left.{ }^{\prime} I^{\prime}\right) 2$ Porcecllings, pp.181-188.

Mayhew D. J. 1992. Principles and Guidelines in Softhware User Interface Design. Englewood Cliffs: Prentice Hall. 1992.

Microsoft 1992. The Winclews Interface, An Application Design Guicle, Microsoft Press, 1992.

Molich R. and Nielsen J. 199(), Improving a humancomputer dialogue. Communications of the ACM, vol. 33, no. 3, 199(), pp.338-348.

Moran T.P. and Carroll J.M. (Eds.) 1994. Design Rationale. Hillsdale: Lawrence Erlbaum. 1994. 
Open Software Foundation 1993. (OSFAMOTIF Sityle (inicle. Revision 1.2, London: Prentice-Hall. 1993.

Reiterer H. 1993, A Human Factors Based User Interface Design, in: Grechenig T. Tscheligi M. (eds.): Human Computer Interaction, Lecture Notes in Computer Science, Springer, 1993, pp.291-3(12.

Reiterer H. 1993a, The Development of Design Aid Tools for a Human Factor Based User Interface Design. in: Conference Proceedings. 1993, IEEE International Conference on Systems, Man and Cybernetics. Volume 4, IEEE, pp.361-366.

Reiterer H. 1994, An enabling system for user interface design, in: Robertson S.A. (ed.): Contemporary ERGONOMICS 1994, Proceedings of the Ergonomic Society's 1994 Annual Conference, Taylor \& Francis. 1994, pp.125-130.

Smith L. S. and Moiser J. 1986, Guiclelines for Designing User Interface Softhware. Bedford: MITRE Corporation, 1986. 